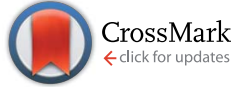

Cite this: RSC Adv., 2015, 5, 17862

Received 12th December 2014 Accepted 3rd February 2015

DOI: 10.1039/c4ra16294c

www.rsc.org/advances

\section{Positively charged, surfactant-free gold nanoparticles for nucleic acid delivery $\dagger$}

\author{
Jianfeng Guo, ${ }^{a}$ Mark J. Armstrong, ${ }^{\text {bc }}$ Caitriona M. O'Driscoll, ${ }^{a}$ Justin D. Holmes ${ }^{\text {bc }}$ \\ and Kamil Rahme*bcd
}

Positively charged, surfactant-free gold nanoparticles (Au NPs) with diameters ranging between 2-200 nm have been synthesised in water via a seed-mediated growth method, involving the reduction of gold(III) chloride $\left(\mathrm{AuCl}_{3}\right)$ by hydroxylamine hydrochloride $\left(\mathrm{NH}_{2} \mathrm{OH} \cdot \mathrm{HCl}\right)$ in the presence of L-cysteine methyl ester hydrochloride $\left(\mathrm{HSCH}_{2} \mathrm{CH}\left(\mathrm{NH}_{2}\right) \mathrm{COOCH}_{3} \cdot \mathrm{HCl}\right)$ as a capping agent. The mercapto group (-SH) on the capping ligand has a high affinity for $\mathrm{Au}$, anchoring the cysteine group to the nanoparticles, whilst the ammonium group $\left(-\mathrm{NH}_{3}{ }^{+}\right)$, formed by the presence of an amine group in slightly acidic media $(\mathrm{pH} \sim 4.5-5)$, resulted in positively charged colloidal nanoparticles ( $\zeta$-potential +33 to $+49 \mathrm{mV}$ ), which was key to their electrostatic stability. Data from cytotoxicity studies performed on a range of different cell types (human and murine), including human prostate cancer cells (PC3), showed that the positively charged $\mathrm{Au}$-L-cysteine-cysteine nanoparticles were less cytotoxic than positively charged Au NPs produced using commonly employed surfactant cetyl trimethyl ammonium bromide (CTAB) under similar conditions. In addition, the positively charged Au NPs could be successfully complexed with small interfering RNA (siRNA). At the cellular level, the uptake of fluorescein siRNA from the charged nanoparticles was comparable to uptake from the commercial carrier INTERFRin ${ }^{T M}$, implying the potential application of these novel vectors for nucleic acid delivery.

\section{Introduction}

Gold nanoparticles (Au NPs) due to their unique physical, chemical and optical properties have been widely used in biomedical applications such as biosensors, clinical chemistry, immunoassays, optical imaging and the monitoring of cells and tissues. ${ }^{1-6}$ As the gold core is generally inert, toxic-free and biocompatible, it is a favourable starting material for carrier construction..$^{7-13}$ For instance, positively charged gold nanoparticles have been developed for drug and gene delivery. ${ }^{\mathbf{1 4 - 1 8}}$ In general, cationic gold nanoparticles are synthesised in the presence of surfactants such as cetyl trimethyl ammonium bromide (CTAB). ${ }^{19-21}$ Of note, positively charged Au nanoprisms have been synthesised by Millstone et al. using a three-step mediated seed growth process in an aqueous solution of CTAB at a concentration of $50 \mathrm{mM}$ (50 times the critical micelle

${ }^{a}$ Pharmacodelivery group, School of Pharmacy, University College Cork, Cork, Ireland ${ }^{b}$ Materials Chemistry and Analysis Group, Department of Chemistry and the Tyndall National Institute, University College Cork, Cork, Ireland

${ }^{c}$ Centre for Research on Adaptive Nanostructures and Nanodevices (CRANN), Trinity College Dublin, Dublin 2, Ireland

${ }^{d}$ Department of Sciences, Faculty of Natural and Applied Science, Notre Dame University (Louaize), Zouk Mosbeh, Lebanon. E-mail: kamil.rahme@ndu.edu.lb; Fax: +961 9 225164; Tel: +9619218950

$\dagger$ Electronic supplementary information (ESI) available. See DOI: $10.1039 / \mathrm{c} 4 \mathrm{ra} 16294 \mathrm{c}$ concentration of CTAB). ${ }^{22}$ In addition, Au nanostructures with shapes ranging from 3D octahedra, triangles, to 2D hexagonal nanoplates have been obtained through changes in the CTAB concentration, used as both a reducing agent and capping ligand during hydrothermal treatment of chloroauric acid. ${ }^{23}$

The successful application of Au nanoparticles in biomedical applications requires tunable particle sizes and morphologies as well as an assessment of their toxicity. ${ }^{\mathbf{2 4 - 2 8}}$ The presence of surfactants during the formation of Au nanoparticles may affect their final size and their shape diversity; this is due to specific adsorption of Au-surfactant complexes on the facets of the nanoparticle seeds that limit their growth and enhance their anisotropic shape. ${ }^{21,29,30}$ In addition, many studies have shown that the biological uptake of positively charged nanoparticles is higher than their negatively charged counterparts, but with positively charged $\mathrm{Au}$ nanoparticles produced from CTAB showing a high level of biological toxicity. ${ }^{31-33}$ Therefore, in the synthesis of Au nanostructures for biological applications, there is a requirement to avoid the use of highly toxic chemicals and surfactants such as CTAB, and move towards surfactant-free synthesis methods. ${ }^{34,35}$

Alternatively, Au NPs using various cationic materials as protecting agents, e.g. amine, polyethylenimine (PEI), poly-Llysine (PLL), poly (diallyl dimethylammonium) chloride (PDDA), cationic chitosan and lipids, have recently been developed to produce positively charged Au NPs for application in the 
delivery of biomolecules. ${ }^{14-18,36-38}$ For instance, Bhumkar and co-workers reported the transmucosal delivery of insulin using chitosan-reduced Au NPs. ${ }^{15}$ In this study, chitosan was used as a reducing agent to produce the Au NPs, and being a polyelectrolyte it also played a role as an electrostatic stabiliser. The oral and nasal administration of insulin formulated with chitosan-reduced $\mathrm{Au}$ NPs improved the pharmacodynamics efficiency in terms of blood glucose levels (BGL) in diabetic rats. ${ }^{15}$ Furthermore, Kong et al. developed cationic lipid-coated Au NPs (L-Au NPs) for the efficient delivery of therapeutic siRNA, ${ }^{16}$ In Kong's study, hydrophobic dodecanethiol-capped Au NPs nanoparticles of about $5 \mathrm{~nm}$ were produced through the reduction of a $\mathrm{Au}(\mathrm{PPh} 3) \mathrm{Cl}$ complex in presence of dodecanethiol using Borane-tert-butylamine complex as reducing agent in benzene, a method well known to produce gold nanoparticles with diameters below $10 \mathrm{~nm}$. These nanoparticles were transferred into water by using a modified emulsification/ solvent evaporation method. ${ }^{16}$ Three different lipid components $\quad \mathrm{L}$ - $\alpha$-dioleoyl phosphatidylethanolamine (DOPE), cholesterol hydrochloride (Chol) and $\left(3 \beta-\left[N-\left(N^{\prime}, N^{\prime}-\right.\right.\right.$ dimethylaminoethane)-carbamoyl]-cholesterol (DC-Chol) were used to coat the hydrophobic dodecanethiol-capped $\mathrm{Au}$ NPs through hydrophobic-hydrophobic interactions. The resultant cationic lipid-coated gold nanoparticles (L-Au NPs) were obtained after several purifications through centrifugation and excessive dialysis with deionised water, after which they were also able to effectively condense siRNA through electrostatic interactions and demonstrated efficient gene knockdown in a variety of cell lines without showing significant cytotoxicity. ${ }^{16}$

In this article we describe a seeded-growth method for synthesising nearly spherical positively charged Au nanoparticles directly in water over a wide range of mean diameters $(2-200 \mathrm{~nm})$, avoiding the use of toxic surfactants and organic solvents such as benzene or toluene. L-Cysteine methyl ester hydrochloride $\left(\mathrm{HSCH}_{2} \mathrm{CH}\left(\mathrm{NH}_{2}\right) \mathrm{COOCH}_{3} \cdot \mathrm{HCl}\right)$ was chosen as the capping agent, because the mercapto group (-SH) is known to have a high affinity for $\mathrm{Au}$, allowing anchoring of cysteine to the nanoparticles, ${ }^{39,40}$ while the ammonium group $\left(-\mathrm{NH}_{3}{ }^{+}\right)$, formed by the presence of an amine group in slightly acid aqueous media, results in positively charged nanoparticles. The presence of the positive charges on the surface of Au NPs is a key to the electrostatic stability of the final aqueous colloidal solution. Additionally, cytotoxicity studies of positively charged $\mathrm{Au}^{-\mathrm{L}^{-}}$ cysteine nanoparticles were performed using human and murine cell lines, showing improved cell viability compared to positively charged and excessively purified Au NPs synthesised using CTAB as a capping ligand. Moreover, Au NPs with diameters greater than $100 \mathrm{~nm}$ demonstrated effective complexation of siRNA (one of RNA interference (RNAi) effectors, a class of double-stranded RNA molecules, which can regulate gene expression post-transcriptionally). The $\mathrm{Au}$ NPs demonstrated comparable cellular uptake of siRNA relative to INTERFRin ${ }^{\mathrm{TM}}$ (a PEI-based commercial transfection reagent), suggesting their role as a promising nucleic acid delivery vector.

\section{Experimental}

\subsection{Chemicals and materials}

Gold(III) chloride $\left(\mathrm{AuCl}_{3}\right)$, sodium borohydride $\left(\mathrm{NaBH}_{4}\right)$, hydroxylamine hydrochloride $\left(\mathrm{NH}_{2} \mathrm{OH} \cdot \mathrm{HCl}\right)$, cetyl trimethyl ammonium bromide (Au NPs-CTAB) were purchased from Sigma Aldrich. L-Cysteine methyl ester hydrochloride $\left(\mathrm{HSCH}_{2} \mathrm{CH}\left(\mathrm{NH}_{2}\right) \mathrm{COOCH}_{3} \cdot \mathrm{HCl}\right)$ was obtained from Fluka. All products were used as received. Purified $\mathrm{H}_{2} \mathrm{O}$ (resistivity $\approx$ $18.2 \mathrm{M} \Omega \mathrm{cm}$ ) was used as a solvent. All glassware was cleaned with aqua regia (3 parts of concentrated $\mathrm{HCl}$ and 1 part of concentrated $\mathrm{HNO}_{3}$ ), rinsed with distilled water, ethanol, and acetone and oven-dried before use.

\subsection{Preparation of Au NPs}

2.2.1. Preparation of $1.9 \pm 0.4 \mathrm{~nm}$ Au NPs-L-cysteine seeds. The original seeds were prepared as follow: to an aqueous solution $(77 \mathrm{~mL})$ of $\mathrm{AuCl}_{3}\left(0.5 \mathrm{mmol} \mathrm{L}^{-1}\right)$ was added $0.75 \mathrm{~mL}$ of a $51.6 \mathrm{mmol} \mathrm{L}^{-1}$ L-cysteine methyl ester hydrochloride solution and the mixture was stirred gently. Afterward $0.27 \mathrm{~mL}$ of an ice cold solution of $\mathrm{NaBH}_{4}\left(144 \mathrm{mmol} \mathrm{L}^{-1}\right)$ was added rapidly. After addition of $\mathrm{NaBH}_{4}$, an instantaneous colour change from pale yellow to deep brown was noted. The resultant nanoparticles obtained had a mean diameter of $1.9 \mathrm{~nm}(\sigma=0.4 \mathrm{~nm})$ as determined from TEM images analysis. The Au NPs-L-cysteine seeds were used in the next hour as seeds for GR1 and GR2 respectively.

2.2.2. Seed-mediated growth of Au NPs. Large diameter $\mathrm{Au}$ nanoparticles were synthesised based on a seed-mediated growth method using hydroxylamine hydrochloride as a reducing agent. ${ }^{40-42}$ In a typical procedure, to an aqueous solution $(50 \mathrm{~mL})$ of $\mathrm{AuCl}_{3}\left(0.5 \mathrm{mmol} \mathrm{L}^{-1}\right)$ was added $0.49 \mathrm{~mL}$ of a $51.6 \mathrm{mmol} \mathrm{L}^{-1}$ L-cysteine methyl ester hydrochloride solution and different volumes of the colloidal seeds solution, the mixture was stirred gently, afterward $0.33 \mathrm{~mL}$ of $115.8 \mathrm{mmol} \mathrm{L}^{-1}$ $\mathrm{NH}_{2} \mathrm{OH} \cdot \mathrm{HCl}$ was added and the solution was stirred for few hours (between 2 and $18 \mathrm{~h}$ ).

For example by adding $40 \mathrm{~mL}$ of the colloidal $\mathrm{Au}$ NPs-Lcysteine seeds solution prepared above, a colour change of the solution from brown to brown slightly reddish was observed. The resultant nanoparticles obtained had a mean diameter of 4 $\pm 1.5 \mathrm{~nm}$ as determined from TEM images analysis and labeled GR1, decreasing volume of the colloidal Au NPs-L-cysteine seeds solution from $40 \mathrm{~mL}$ to $25 \mathrm{~mL}$, resulted nanoparticles with mean diameter of $5.5 \pm 2 \mathrm{~nm}$ as determined from TEM images analysis and labeled GR2. In order to avoid increasing the polydispersity of the samples a successive growth was used, therefore, for GR3 Au NPS-L-cysteine diameter of $7 \pm 2.5 \mathrm{~nm}$ as determined from TEM images analysis, 20 mL of GR2 Au NPs-Lcysteine solution prepared above were used as seeds and the solution was stirred for approximately $4 \mathrm{~h}$. For the rest of the samples the GR4-G12 the size was determined using SEM. For GR4 Au NPs-L-Cysteine diameter of $9 \pm 4 \mathrm{~nm} 20 \mathrm{~mL}$ of GR3 Au NPs-L-cysteine were used as seeds (added to $40 \mathrm{~mL} \mathrm{AuCl}_{3}$ $0.5 \mathrm{mmol} \mathrm{L}^{-1}$ ). For GR5 Au NPs-L-cysteine diameter of $16 \pm 2 \mathrm{~nm}$, $10 \mathrm{~mL}$ of GR4 Au NPs-L-cysteine solution were used as seeds. 
For GR6 Au NPs-L-cysteine diameter of $46 \pm 4 \mathrm{~nm}, 10 \mathrm{~mL}$ of GR5 Au NPs-L-cysteine solution were used as seeds. For GR7 Au NPsL-cysteine diameter of $56 \pm 4 \mathrm{~nm}, 5 \mathrm{~mL}$ of GR5 Au NPs-L-cysteine seeds solution were used. For GR8 Au NPs-L-Cysteine diameter of $80 \pm 6 \mathrm{~nm}, 5 \mathrm{~mL}$ of GR6 Au NPs-L-cysteine solution were used as seeds. For GR9 Au NPs-L-cysteine diameter of $104 \pm 7 \mathrm{~nm}, 5 \mathrm{~mL}$ of GR7 Au NPs-L-cysteine solution were used as seeds. For GR10 Au NPs-L-cysteine diameter of $118 \pm 9 \mathrm{~nm}: 1.5 \mathrm{~mL}$ of GR7 Au NPs-Lcysteine were used as seeds (added to $28.3 \mathrm{~mL}$ of $\mathrm{AuCl}_{3} 0.5 \mathrm{mmol}$ $\left.\mathrm{L}^{-1}\right)$. For GR11 $(145 \pm 18 \mathrm{~nm})$ and $G R 12(195 \pm 20 \mathrm{~nm}) \mathrm{Au} \mathrm{NPs-L^{- }}$ cysteine, $5 \mathrm{~mL}$ and $1 \mathrm{~mL}$ of GR10 Au NPs-L-cysteine solution used as seeds respectively (added to $28.3 \mathrm{~mL}$ of $\mathrm{AuCl}_{3} 0.5 \mathrm{mmol} \mathrm{L}^{-1}$ ).

2.2.3. Au NPs-CTAB and Au NPs-CTAB/L-cysteine diameter of $20 \pm 4 \mathbf{~ n m}$ and $60 \pm 8 \mathbf{~ n m}$. Solutions of Au NPs-CTAB, with a mean diameter of approximately $20 \mathrm{~nm}$, were prepared by a previously reported seeding growth method using ascorbic acid as a reducing agent in the presence of CTAB and Au NPs seeds and purified by centrifugation (45 $\min 11000 \mathrm{rpm}$ ) and redispersion in water. ${ }^{43}$ Solutions of Au NPs-CTAB with mean diameters around $60 \mathrm{~nm}$ were synthesised in a similar method used for the Au NPs-cysteine solutions, with the only difference that the 20 $\mathrm{nm} \mathrm{Au} \mathrm{NPs-CTAB} \mathrm{solutions} \mathrm{were} \mathrm{used} \mathrm{as} \mathrm{seeds.} \mathrm{Briefly,} \mathrm{to} \mathrm{an}$ aqueous solution $(40 \mathrm{~mL})$ of $\mathrm{AuCl}_{3}\left(0.6 \mathrm{mmol} \mathrm{L}{ }^{-1}\right)$ was added 14 $\mathrm{mL}$ of $20 \mathrm{~nm} \mathrm{Au} \mathrm{NPs-CTAB}$ and L-cysteine methyl ester hydrochloride $\left(0.5 \mathrm{mmol} \mathrm{L}^{-1}\right)$ the mixture was stirred gently afterward $0.33 \mathrm{~mL}$ of $115.8 \mathrm{mmol} \mathrm{L}^{-1} \mathrm{NH}_{2} \mathrm{OH}, \mathrm{HCl}$ was added and the solution was stirred for approximately $18 \mathrm{~h}$. The resultant nanoparticles obtained had a mean diameter of $60 \mathrm{~nm}(\sigma=8 \mathrm{~nm})$.

\subsection{UV-visible spectroscopy}

Optical absorption spectra were obtained on a CARY UV-visible spectrophotometer with a Xenon lamp (300-900 $\mathrm{nm}$ range, $0.5 \mathrm{~nm}$ resolution).

\subsection{Particle size and zeta potential measurements}

The pristine solutions of Au NPs were measured by dynamic light scattering (DLS). The measurements were undertaken with a Malvern instrument (Zeta sizer Nano Series) at $25^{\circ} \mathrm{C}$ using the default non-invasive back scattering (NIBS) technique with a detection angle of $173^{\circ}$. Three measurements were made per sample and the standard deviation $(\sigma)$ was calculated, typically $\sigma=1-2 \mathrm{~nm}$.

\subsection{Transmission electron microscopy}

$\mathrm{Au}$ nanoparticles were placed on carbon-coated copper grids (Quantifoil, Germany) and dried over night in air, prior to transmission electron microscope (TEM) inspection. The samples were inspected using a JEOL JEM-2100 TEM operating at $200 \mathrm{kV}$. Micrographs were recorded on a Gatan $1.35 \mathrm{~K} \times$ $1.04 \mathrm{~K} \times 12$ bit ES500W CCD camera. TEM images were analysed using Image $\mathrm{J}$ software.

\subsection{Scanning electron microscopy}

$\mathrm{Au}$ nanoparticles were deposited from solution onto a Si wafer and dried in air prior to inspection by scanning electron microscope (SEM). The samples were inspected using a FEI 630 NanoSEM equipped with an Oxford INCA energy dispersive $\mathrm{X}$-ray (EDX) detector, operating at $5 \mathrm{kV}$.

\subsection{Cell culture and cytotoxicity}

Hep G2, Caco-2, PC-3, B16F10 and CT26 cell lines were purchased from the European Collection of Cell Cultures (ECACC), UK. Hep G2 (human hepatocellular carcinoma cell line) and Caco-2 (human colorectal adenocarcinoma cell line) cells were maintained in DMEM medium (Sigma) supplemented with $10 \%$ FBS and 2 mM L-glutamine. ${ }^{44,45}$ PC-3 (human prostate carcinoma cell line), B16F10 (mouse melanoma cell line) and CT26 (mouse colon carcinoma cell line) cells were maintained in RPMI medium (Sigma) supplemented with 10\% FBS. ${ }^{4-48}$ These cells (passage number $<30$ ) were grown in the incubator (ThermoForma) at $37{ }^{\circ} \mathrm{C}$ with $5 \% \mathrm{CO}_{2}$ and $95 \%$ relative humidity.

The cytotoxicity of Au NPs was estimated using the MTT assay with 3-(4,5-dimethylthiazol-2-yl)-2,5-diphenyltetrazolium bromide (Sigma). ${ }^{46}$ Hep G2 (20 000 cells per well), Caco-2 (10 000 cells per well), PC-3 (5000 cells per well), B16F10 (1000 cells per well) and CT26 (6000 cells per well) cells were seeded within $200 \mu \mathrm{L}$ growth media in 96-well plates one day before transfection. Au NPs were incubated with cells for $24 \mathrm{~h}$ under the normal growth conditions. After incubation, the particle solution was replaced with $200 \mu \mathrm{L}$ fresh growth medium, and $20 \mu \mathrm{L}$ MTT stock ( $5 \mathrm{mg} \mathrm{mL}^{-1}$ in PBS) was added and incubated with cells for $4 \mathrm{~h}$ at $37^{\circ} \mathrm{C}$. The contents were removed and $100 \mu \mathrm{L}$ DMSO was added to dissolve the purple formazan products. The data were obtained at $590 \mathrm{~nm}$ using a microplate reader. The concentration of Au NPs leading to $50 \%$ cell growth inhibition (IC50) was estimated from the plot of the percentage of viable cells versus the concentration of $\mathrm{Au}$ NPs for each treatment.

\subsection{Preparation and characterisation of Au NP·siRNA complexes}

A colloidal solution of Au NPs $\left(100 \mu \mathrm{g} \mathrm{mL}^{-1}\right)$ were added into an siRNA solution (siRNA, sense sequence $5^{\prime}$-UUC UCC GAA CGU GUC ACG U-3', was obtained from QIAGEN, USA and prepared in RNase-free water following QIAGEN recommendations), at different mass ratios (MRs) of Au NPs to siRNA, followed by $1 \mathrm{~h}$ incubation with slightly shaking at RT. The ability of Au NPs to complex siRNA was analysed by gel retardation. ${ }^{49}$ Briefly, complexes of $\mathrm{Au}$ NPs and siRNA (containing $0.25 \mu \mathrm{g}$ siRNA) at different mass rations (MRs) were loaded onto 1\% (w/v) agarose gels in Tris/Borate/EDTA (TBE) buffer containing SafeView (NBS Biologicals, UK). Electrophoresis was performed at $120 \mathrm{~V}$ for 30 min and the resulting gels were photographed under UV. In addition, particle sizes and zeta potentials were measured with a Malvern Nano-ZS (Malvern Instruments, UK) at $25{ }^{\circ} \mathrm{C}$ using the default non-invasive back scattering (NIBS) technique with a detection angle of $173^{\circ} .^{50}$ Deionised water $(0.2 \mu \mathrm{m}$ membranefiltered, applied for particle size and zeta potential evaluation) were added to the complexes (Au-siRNA complexes at different 
MRs) and made up to $1 \mathrm{~mL}$, before measurement. The concentration of siRNA was fixed at $1 \mu \mathrm{g} \mathrm{mL} \mathrm{m}^{-1}$.

\subsection{Fluorescence activated cell sorting}

PC-3 cells (50 000 per well) were seeded in 24-well plates and incubated for $24 \mathrm{~h}$ under normal growth conditions. Cells were then transfected by $20 \mathrm{nM}$ fluorescein-siRNA complexed with GR11 (MR20) and incubated for $24 \mathrm{~h}$ in normal growth medium. Fluorescein-siRNA alone was used as the negative control, and fluorescein-siRNA complexed with INTERFRin ${ }^{\mathrm{TM}}$ (Polyplus) (prepared following the manufacturer's recommendation) was used as the positive control. On the following day, cells were first treated with CellScrub ${ }^{\mathrm{TM}}$ (Genlatins) to remove complexes associated with cell surfaces (uninternalised complexes) according to manufacturer's instructions. The medium was then removed, and cells were washed twice with PBS and trypsinised. Cells were subsequently centrifuged $(1000 \mathrm{rpm}$ for $5 \mathrm{~min}$ ) and were re-suspended in $1000 \mu \mathrm{L}$ cold PBS in polystyrene round-bottom tubes (Becton Dickinson). Ten thousands cells were measured for each sample following the application of Becton Dickinson FACScalibur manual. Fluorescein-positive cells (\%) were displayed by Dot Plot.

\subsection{Statistics}

One-way analysis of variance (ANOVA) was used to compare multiple groups followed by Bonferroni's post hoc test. Statistical significance was set at $* p<0.05$.

\section{Results and discussion}

\subsection{Synthesis and characterisation of positively charged Au} NPs

The aim of our study was to form nearly spherical positively charged Au nanoparticles in water, with a wide mean diameter range, avoiding the use of toxic surfactants that may direct the final shape/size and biocompatibility of the nanoparticles. Typical synthesis methods for the production of positively charged gold nanoparticles employ the cationic surfactant CTAB as a capping and stabilising agent. CTAB forms a bilayer structure around Au NPs, with the inner layer binding to the $\mathrm{Au}$ surface via its charged head groups and the adsorbed bilayer leads to a net positive charge on the surface of the nanoparticles. ${ }^{51}$ These methods use very high concentration of CTAB that can often affect the final size and shape of the nanoparticles formed; for instance, CTAB is the most widely used surfactant for the synthesis of anisotropic multiple shapes of $\mathrm{Au}$ NPs such as nanorods or nanoprisms. ${ }^{52}$ Previous studies have shown that the presence of CTAB during seed-mediated growth methods leads to the formation of Au nanorods with aspect ratios ranging from 1.5 to $4.5,{ }^{53}$ while the addition of a cosurfactant such as benzyldimethylhexadecylammonium chloride (BDAC) to CTAB yields the formation of a binary surfactant mixture that affects the aspect ratios of the Au nanorods, varying from 4.6 to $10 .^{54}$ However, Au-CTAB nanoparticles are known to be highly toxic to different cell lines, due to the presence of excess surfactant..$^{31,32,55}$ Our hypothesis in this study was that by producing colloidal solutions free of surfactants such as CTAB, low toxic Au NPs with a desired morphology can be obtained. ${ }^{21}$

Ultra small $\mathrm{Au}-\mathrm{L}-\mathrm{cysteine}$ methyl ester seeds, with a mean diameter around $2 \mathrm{~nm}$, were obtained by reducing $\mathrm{AuCl}_{3}$ with ice cold $\mathrm{NaBH}_{4}$ in the presence of L-cysteine methyl ester hydrochloride as a stabilising agent (Fig. S1 $\dagger$ ). The $\mathrm{Au}_{-} \mathrm{L}^{-}$ cysteine methyl ester seeds obtained were further used to produce samples GR1 and GR2, by the surface catalysed reduction of $\mathrm{AuCl}_{3}$ with hydroxylamine hydrochloride, yielding an increased population of the seeds with mean diameters between 4-5 $\mathrm{nm}$. As the cysteine solution contains hydrochloride, $\mathrm{AuCl}_{3}$ was chosen as a precursor in this study instead of tetrachloroauric acid $\mathrm{HAuCl}_{4}$ in order to avoid increasing the acidity of the aqueous solution, which would affect the synthesis process and the final particle size and aggregation state. Data in Table 1 and Fig. S1 $\uparrow$ obtained from TEM images show that nanoparticles generated in samples GR1 and GR2 were well below $10 \mathrm{~nm}(4 \pm 1.5 \mathrm{~nm}$ and $5 \pm 2 \mathrm{~nm}$ respectively $)$

Table 1 Characterisation of Au NP samples (GR1 to GR12) by UV-visible, EM and DLS

\begin{tabular}{|c|c|c|c|c|c|c|c|c|c|}
\hline $\begin{array}{l}\text { Sample } \\
\text { name }\end{array}$ & $\begin{array}{l}\lambda_{\max } \\
(\mathrm{nm})\end{array}$ & $\begin{array}{l}\Delta \lambda \\
(\mathrm{nm})\end{array}$ & $A_{\max }$ & $\begin{array}{l}\text { Diameter } \\
(\mathrm{nm}) \mathrm{EM}\end{array}$ & $\begin{array}{l}\text { Standard } \\
\text { dev. }\end{array}$ & $\begin{array}{l}\text { Hydrodynamic } \\
\text { diameter } \\
(\mathrm{nm}) \mathrm{DLS}\end{array}$ & PDI & $\begin{array}{l}\text { Zeta potential } \\
(\mathrm{mV})\end{array}$ & $\begin{array}{l}\text { Zeta deviation } \\
(\mathrm{mV})\end{array}$ \\
\hline Seeds & - & - & - & 1.9 & 0.4 & - & - & 38.3 & 14.6 \\
\hline GR1 & 519 & 70 & 0.78 & 4 & 1.5 & 4.2 & 0.46 & 34.8 & 11.5 \\
\hline GR2 & 521 & 86 & 0.94 & 5.5 & 2 & 5.1 & 0.55 & 35.1 & 14 \\
\hline GR3 & 521 & 89 & 0.96 & 7 & 3 & 24 & 0.6 & 34.8 & 17.1 \\
\hline GR4 & 522 & 91 & 1.12 & 9 & 4.5 & 7 & 0.5 & 33.2 & 18 \\
\hline GR5 & 524 & 89 & 1.15 & 16 & 2 & 19 & 0.2 & 34 & 14.3 \\
\hline GR6 & 629 & 87 & 1.09 & 46 & 4 & 47 & 0.14 & 34.9 & 18.1 \\
\hline GR7 & 533 & 93 & 0.98 & 56 & 4 & 55 & 0.11 & 37.6 & 16.4 \\
\hline GR8 & 554 & 126 & 1.16 & 80 & 6 & 86 & 0.07 & 45.4 & 13.5 \\
\hline GR9 & 572 & 160 & 0.94 & 104 & 7 & 104 & 0.07 & 44.3 & 11.8 \\
\hline GR10 & 576 & 171 & 0.8 & 118 & 9 & 117 & 0.07 & 49 & 12.3 \\
\hline GR11 & 607 & 251 & 0.56 & 145 & 18 & 139 & 0.10 & 41.2 & 10.8 \\
\hline GR12 & 2 peaks & $>380$ & $\sim 0.2$ & 195 & 20 & 195 & 0.15 & 41.6 & 11.1 \\
\hline
\end{tabular}


with a relatively high large size-polydispersity (PDI $>0.45$ ); most likely due to the excess of $\mathrm{NaBH}_{4}$ used in the seed solutions causing the formation of some new $\operatorname{Au}(0)$ nuclei. The size polydispersity and diverse shape formation was reduced during synthesis, by growing the nanoparticles in a stepwise fashion. ${ }^{56-60}$ Therefore, for the rest of the gold colloidal solutions GR3-GR12 a successive growth method was used and GR2 seeds $5 \pm 2 \mathrm{~nm}$ were ripened to $\sim 7 \pm 2.5 \mathrm{~nm}$ (GR3), the latter was ripened to form GR4 nanoparticle solutions (diameters $9 \pm$ $4 \mathrm{~nm}$ ) that were ripened to form GR5 nanoparticle solutions (diameters $16 \pm 2 \mathrm{~nm}$ ) (Table 1). GR6 and GR7 nanoparticle solutions (diameters $46 \pm 4 \mathrm{~nm}$ and $56 \pm 4 \mathrm{~nm}$ respectively) were prepared from GR5 solutions by varying the concentration of the nanoparticle seeds. GR6 nanoparticle solutions (diameters $46 \pm 4 \mathrm{~nm}$ ) were ripened to $80 \pm 6 \mathrm{~nm}$ (GR8 nanoparticle samples). GR9 and GR10 nanoparticle samples (diameters 104 $\pm 7 \mathrm{~nm}$ and $118 \pm 9 \mathrm{~nm}$ respectively) were prepared from GR7 solutions by varying the concentration of the nanoparticle seeds, and finally GR11 and GR12 nanoparticle samples (diameters $145 \pm 18 \mathrm{~nm}$ and $195 \pm 20 \mathrm{~nm}$ respectively) were prepared from GR10 solutions by varying the concentration of the nanoparticle seeds. The successive growth method used in this study allowed us to obtain nearly spherical and sizemonodisperse Au NPs-cysteine samples (GR5-GR12) as confirmed by SEM (Fig. 2) and DLS $(0.07<$ PDI $<0.2)$ analysis (Table 1).

\subsection{UV-visible absorption spectroscopy, EM and DLS}

Table 1 summarises the UV-visible absorption spectroscopy (Fig. 1) and either TEM or SEM Fig. S1 $\uparrow$ and 2 data obtained from the Au NPs. The UV-visible spectra of the seeds showed that the nanoparticles had no clear plasmon band, indicating that they were ultra-small in size, as the plasmon band disappears when the size of Au clusters approaches $2 \mathrm{~nm}$ (Fig. 1(a)). ${ }^{61}$ TEM data also verified that the mean diameter of the seeds was around $1.9 \mathrm{~nm}(\sigma=0.4 \mathrm{~nm})$ (Fig. $\mathrm{S} 1 \dagger)$. As the size of the nanoparticles was increased from $4 \pm 1.5 \mathrm{~nm}$ (GR2) to $\sim 80 \pm 6$ $\mathrm{nm}$ (GR8) a slight increase in the absorbance from $\sim 0.78$ to $\sim 1.15$ (GR8) was observed, accompanied by a red shift in the plasmon band from 519 to $554 \mathrm{~nm} .{ }^{\mathbf{4 0 , 6 2}}$ However, when the size of the nanoparticles increased above $80 \mathrm{~nm}$ in diameter a decrease in the plasmon absorbance was noticed, i.e. from $\sim 1.15$ for (GR8) to $\sim 0.56$ (GR11), with a plasmon band red shift more prominent from $554 \mathrm{~nm}$ (GR8) to $607 \mathrm{~nm}$ (GR11) when the Au NP diameter increased from $80 \pm 6 \mathrm{~nm}$ (GR8) to $145 \pm 18 \mathrm{~nm}$ (GR11). The observed red shift was also accompanied by a further broadening of the absorbance band. The band width $\left(\lambda_{0}\right)$ was found to increase by about $24 \mathrm{~nm}$ from 70 to $91 \pm 3 \mathrm{~nm}$ when the mean nanoparticle diameter increased from $4 \mathrm{~nm}$ (GR1) to $56 \mathrm{~nm}$ (GR7), and by approximately $147 \mathrm{~nm}$ from 94 to $251 \mathrm{~nm}$ when the mean nanoparticle diameter increased from $56 \mathrm{~nm}$ (GR7) to $145 \mathrm{~nm}$ (GR11). Finally, the GR12 nanoparticle solutions (diameters $\sim 195 \mathrm{~nm}$ ) displayed poorly defined two peaks with a broad absorption between 520-900 nm (Fig. 1(b) $)^{\mathbf{4 0 , 6 2}}$ The broadening of the absorbance band and peak shift became more pronounced when the size of the nanoparticles increased above $50 \mathrm{~nm}$; this can be explained by the fact that higher oscillation modes (quadrupole, octopole absorption and scattering) may also affect the nanoparticle extinction cross sections with increasing size. ${ }^{62,63}$ The electron microscopy images in Fig. 2 and S1 $\uparrow$ show that the nanoparticle diameter distribution widths and circularity were not strongly affected by increasing the diameter (no nanorods or other particular shapes were detected) and therefore comparable diameter distribution widths and nanoparticle circularity to the initial spherical seeds were observed.

\subsection{Dynamic light scattering}

DLS, combined with electron microscopy can provide a full physical characterisation of colloidal dispersions of Au NPs for
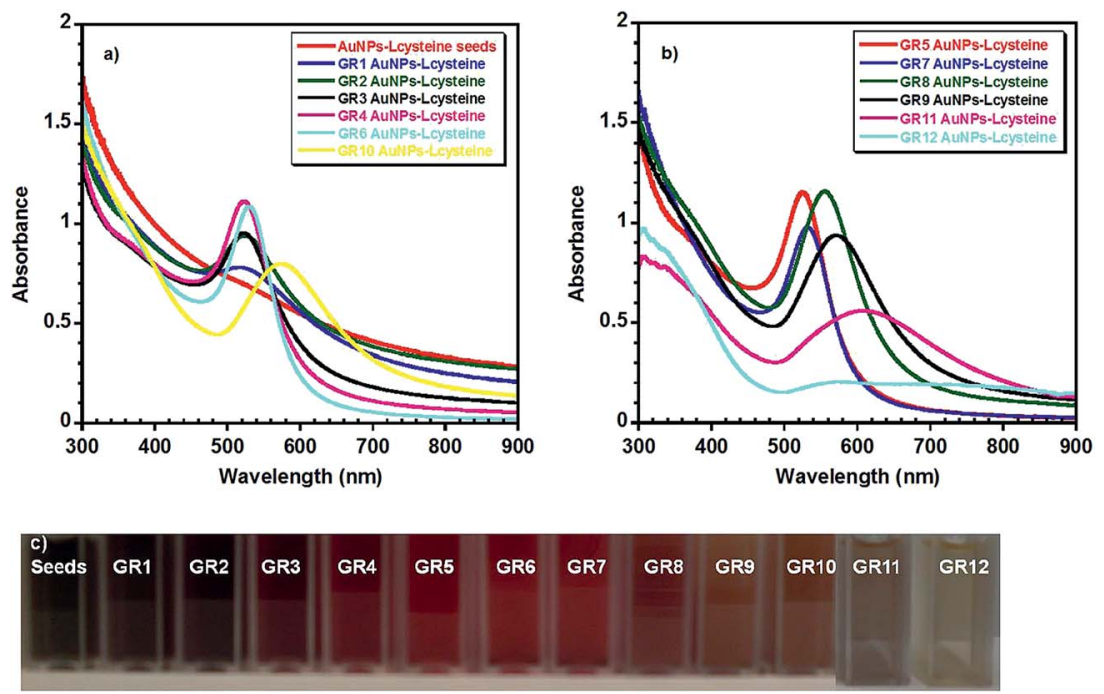

Fig. 1 (a) and (b) UV-visible spectra of different Au NPs. The spectra were split for better visualisation. Samples in (b) were used in the cytotoxicity assays. (c) Optical photographs of the corresponding colloidal solutions. 

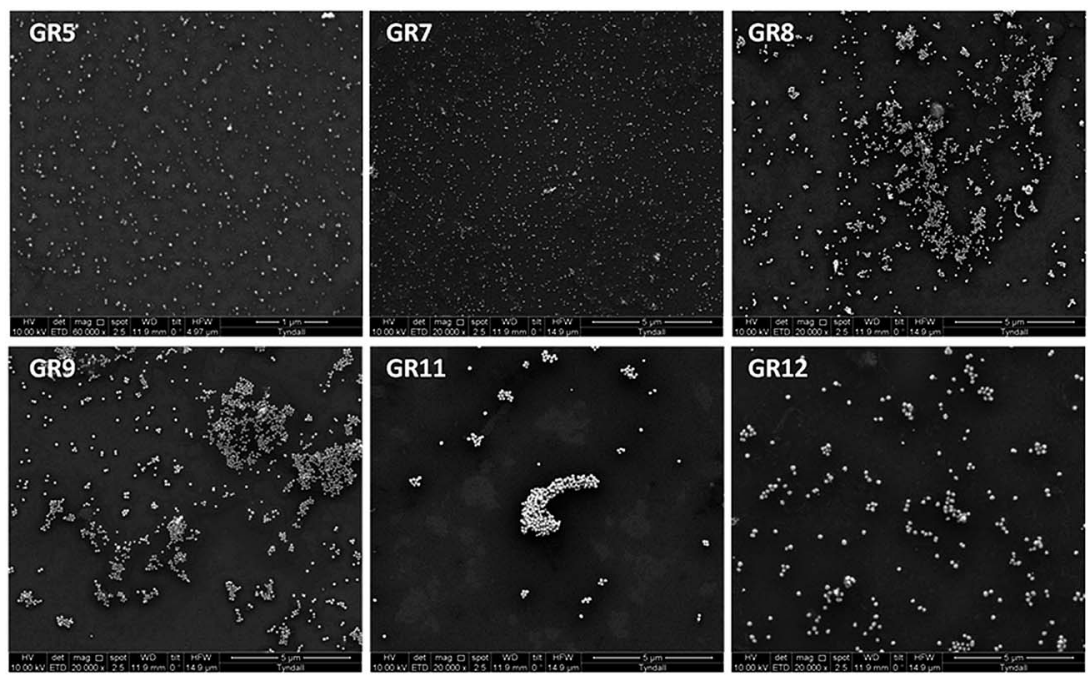

Fig. 2 SEM of Au NPs with mean diameters of (GR5) 16 nm, (GR7) $56 \mathrm{~nm}$, (GR8) $80 \mathrm{~nm},(\mathrm{GR9}) \sim 104 \mathrm{~nm},(\mathrm{GR} 11) \sim 145 \mathrm{~nm}$ and $(\mathrm{GR} 12) \sim 195$ $\mathrm{nm}$.
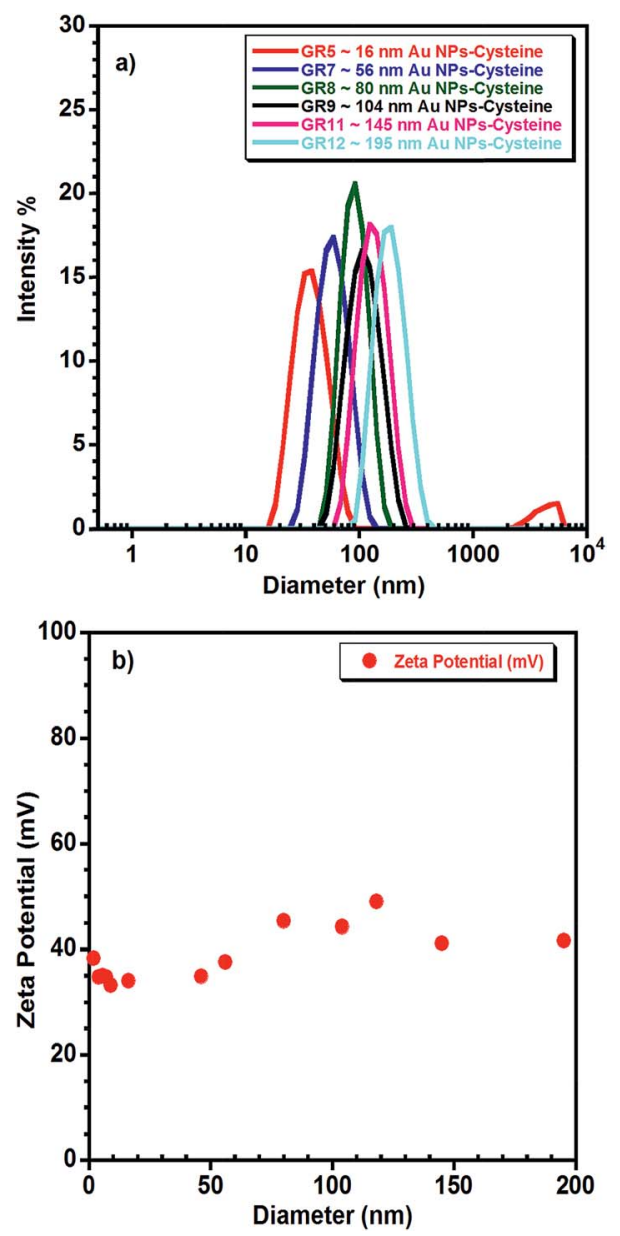

Fig. 3 (a) Size distribution by intensity for the Au NP-L-cysteine methyl ester hydrochloride (GR5, GR7 to GR12, these were used in the cytotoxicity assays). (b) Zeta Potential for Au NPs (G1 to G12). biomedical applications. The zeta potential measurements can also be measured by DLS. Fig. 3(a) shows the size distribution, by intensity, of samples GR5, GR7, GR8, GR9, GR11 and GR12 and Fig. 3(b) highlights the zeta potentials $(\mathrm{mV})$ of all of the $\mathrm{Au}$ NPs-cysteine solutions synthesised in this study. For Au NP samples with diameters below $10 \mathrm{~nm}$ (GR1-GR4), size distributions were difficult to measure by DLS; samples GR1-GR4 were slightly size-polydisperse with a polydispersity index (PDI) around $0.53 \pm 0.06$. However, larger nanoparticle samples GR5 $(16 \mathrm{~nm})$ to GR12 (195 nm) were nearly size-monodisperse with a PDI around $0.13 \pm 0.06$, and a measured hydrodynamic diameter $\left(D_{\mathrm{h}}\right)$ very close to the diameters obtained from EM analysis (see Table 1). The zeta potential of all of the nanoparticle samples prepared in this study showed a positive value around $+39 \pm 5$ (Fig. 3(b) and $\mathrm{S} 2 \dagger$ ) indicating that the nanoparticles were successfully coated with a positively charged capping layer of L-cysteine methyl ester hydrochloride $\left(0.5 \mathrm{mmol} \mathrm{L}^{-1}\right)$, which provided colloidal stability.

\subsection{Cytotoxicity}

A comparison of the cytotoxicity of Au nanoparticle solutions of GR5, GR7, GR8, GR9, GR11 and GR12 with Au NPs-CTAB samples was performed using a range of human and murine cells (Fig. 4 and Table S1 $\dagger$ ). The cytotoxicity of Au NPs was studied using an MTT assay. In the PC-3 cell line, GR5, GR7, GR8, GR9, GR11 and G12 samples displayed IC50 values of 8.2, $7.8,8.2,7.4,8.5$ and $8.0 \mu \mathrm{g} \mathrm{mL}^{-1}$ respectively. In contrast, $\mathrm{Au}$ NP-CTAB samples (20 and $60 \mathrm{~nm}$ ) caused a higher level of cytotoxicity with IC50 values of 2 and $3.5 \mu \mathrm{g} \mathrm{mL} \mathrm{m}^{-1}$ respectively (Table S1 $\dagger$ ). In addition, similar data were observed in Hep G2, Caco-2, B16F10 and CT26 cells (Table S1†). Goodman et al. have previously reported that positively charged CTAB-stabilised Au NPs may cause higher cytotoxicity compared to their anionic carboxylate stabilised counterparts. Here we have demonstrated that Au NP-CTAB samples (20 and $60 \mathrm{~nm}$ ) caused higher cell 


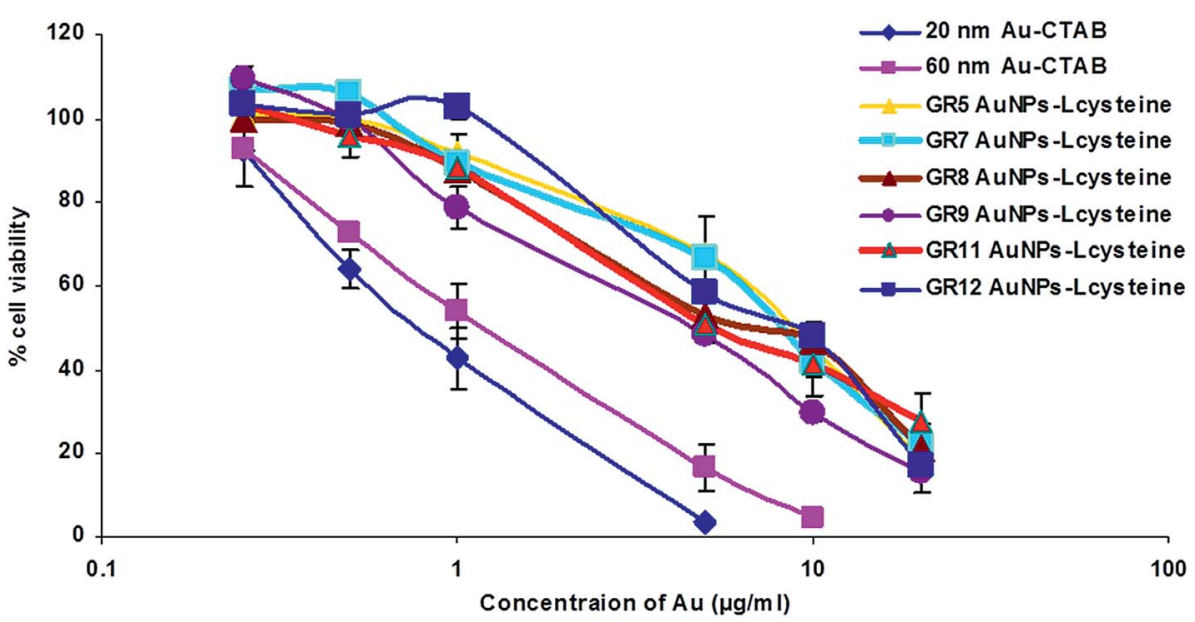

Fig. 4 Viability (MTT) of PC-3 cells treated with Au NPs (mean $\pm S D, n=3$ ).

death compared to non-CTAB Au-L-cysteine nanoparticles (Fig. 4 and Table S1†).

Cationic Au nanoparticles in general have been reported to cause high toxicity ${ }^{64}$ and demonstrate in vivo instability due to aggregation followed by non-specific uptake by the mononuclear phagocytic system (MPS, also known as the reticuloendothelial system (RES)). ${ }^{65}$ One of the best characterised methods to improve the biocompatibility and in vivo stability of cationic Au NPs is the addition of polyethylene-glycol (PEG, a highly soluble, non-toxic and non-immunogenic polymer, approved for use by the Food and Drug Administration (FDA)).

\subsection{Formation of Au NP·siRNA complexes}

Recently, Au NPs have been functionalised by grafting cationic polymers and biomolecules onto the surface of gold in order to bind negatively charged nucleic acid via electrostatic interaction achieving a complex. ${ }^{16,17,66}$ In addition, thiol (SH)-functionalised nucleic acids have also been used to attach nucleic acid onto Au NPs thus forming a complex due to the high affinity of thiol to gold to produce AuNP-thiolates $(\mathrm{Au}-\mathrm{S}){ }^{67-70}$ In this study siRNA was chosen to examine the capacity of Au NPs to deliver nucleic acids. The formation of Au NP.siRNA complexes through the interaction between the positively charged amino groups on the surface of the Au NPs and negatively charged siRNA was examined by gel retardation (Fig. 5). As can be seen from Fig. 5 the complete complexation of siRNA with GR11 nanoparticle samples took place from a mass ratio (MR) of 20 onwards. The complexation of siRNA using Au NPs with smaller diameters $(<100 \mathrm{~nm})$ was not as efficient as with larger NPs $(>100 \mathrm{~nm})$ (Fig. S3 $\uparrow$ ), suggesting that siRNA did not easily complex around small particles because of the stiff rod-like structure of siRNA. ${ }^{71}$

The GR11 - siRNA complex at MR20 demonstrated a cationic surface $(\sim+25 \mathrm{mV})$, in comparison with negatively charged counterparts at MR5 and 10 ( $\sim-22$ and $-11 \mathrm{mV}$, respectively), confirming that siRNA was efficiently complexed with GR11 at MR20 onwards (Fig. 5). In addition, the mean diameters of GR11.siRNA complexes at MR20 in DI water were in the diameter range of $155 \pm 15 \mathrm{~nm}$; whereas, a significant increase in size (>1000 nm) occurred for GR11 - siRNA complexes at MR5 and MR10. These data suggest that the positively charged formulation effectively prevented aggregation in comparison with the negatively charged counterparts, indicating that cationic materials may remain stable in solution. ${ }^{72}$ However, previous studies have shown that aggregation of positive complexes is time dependent. ${ }^{73}$ In addition to improving cell viability, PEGylation has been reported to stabilise complexes against salt-, protein- and complement-induced inactivation by steric effects as well as by shielding surface charges. ${ }^{39,74,75}$ Future studies will produce PEGylated $\mathrm{Au}-\mathrm{L}$-cysteine nanoparticles and will examine the physicochemical, in vitro and in vivo profiles of these vectors for siRNA delivery.

\subsection{Internalisation of Au NP'siRNA complexes}

Fluorescein-siRNA was used to study the internalisation of $\mathrm{Au}$ NP-siRNA complexes in PC-3 cells. The fluorescein-siRNA formulated with GR11 (MR20) significantly increased cellular uptake compared to fluorescein-siRNA alone; in addition, GR11

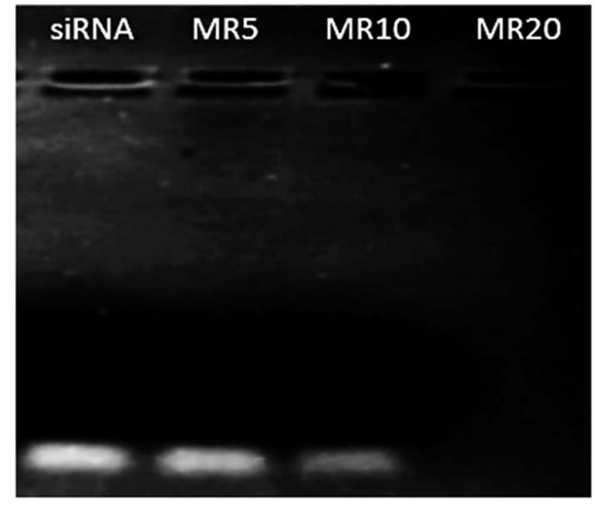

Fig. 5 Complexation of siRNA $(0.25 \mu \mathrm{g})$ with GR11 samples at different mass ratios (MRs of Au NPs to siRNA, MR $=5,10$ and 20). $0.25 \mu \mathrm{g}$ of siRNA was used as negative control. 


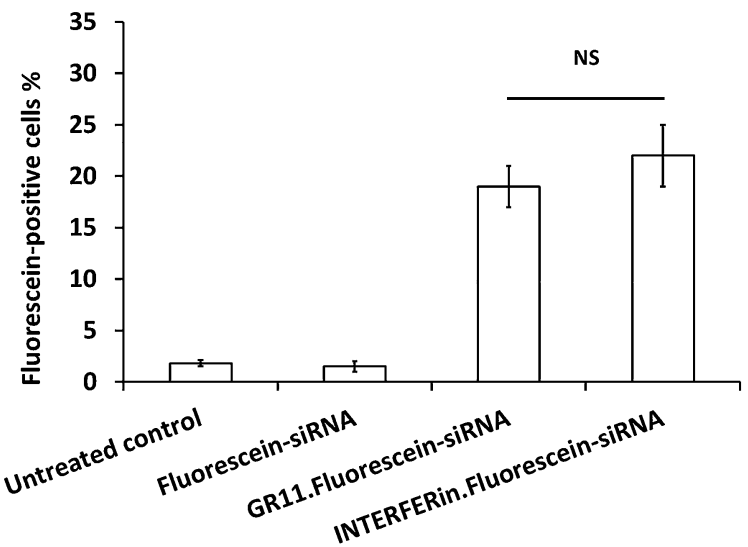

Fig. 6 Fluorescein-positive cells (\%) with 20 nM fluorescein-siRNA either uncomplexed and complexed with GR11 (MR20) and INTERFERin $^{\mathrm{TM}}$, analysed by Dot Plot in PC-3 cells (NS $=$ no significance) (mean $\pm \mathrm{SD}, n=3$ ).

achieved similar cellular uptake (up to $20 \%$ ) compared to INTERFERin ${ }^{\mathrm{TM}}$ (up to 25\%) (Fig. 6; the representative Dot Plots showing fluorescein-positive cells (\%) are shown in Fig. S4†), suggesting that the Au NPs were able to deliver nucleic acids into the cells. In addition, further bioconjugation via the ammonium group and hydroxyl protected (o-methyl ester) functional group on the surface of these Au NPs can be used to improve intracellular trafficking of nucleic acids into the cytoplasm, in the case of antisense oligodeoxynucleotide (ODN), siRNA and microRNA (miRNA), or the nucleus, in the case of plasmid DNA and short hairpin RNA (shRNA), with the overall aim of regulating gene expression. ${ }^{76}$

\section{Conclusions}

Positively charged, surfactant-free and nearly spherical Au NPs have been synthesised in water with a wide range of diameters ( 2 to $200 \mathrm{~nm}$ ) and narrow diameter distributions $10-15 \%$ (with the exception for the sizes below $10 \mathrm{~nm}$ ), using a controlled seed mediated growth approach. These Au NPs showed sizedependent optical properties making them very suitable for photonic and bioimaging applications. The presence of L-cysteine methyl ester hydrochloride $\left(\mathrm{HSCH}_{2} \mathrm{CH}\left(\mathrm{NH}_{2}\right)\right.$ $\left.\mathrm{COOCH}_{3} \cdot \mathrm{HCl}\right)$ on their surface with a mercapto group $(-\mathrm{SH})$ anchoring the cysteine to the nanoparticles and an ammonium group $\left(-\mathrm{NH}_{3}{ }^{+}\right)$formed by the presence of an amine group in slightly acidic media confer positive charges to the resulting $\mathrm{Au}$ NP as confirmed from the zeta potential measurements ( $\zeta$-potential +33 to $+49 \mathrm{mV}$ ). In addition, cytotoxicity studies performed in a range of human and murine cell lines demonstrated that the surfactant-free positively charged Au NPs synthesised in this study were less cytotoxic than Au-CTAB nanoparticles. Furthermore, Au NPs with diameters over 100 $\mathrm{nm}$ formed effective complexes with nucleic acids. In comparison with commercially available transfection reagent, these complexes demonstrated similar capacity to deliver nucleic acids, in terms of cellular uptake of fluorescein siRNA.
Moreover, the presence of the ammonium group and hydroxyl protected ( $o$-methyl ester) functional group on the surface of these $\mathrm{Au}$ NPs indicates the potential of Au NPs-L-cysteine methyl ester for further chemical bioconjugation to facilitate active targeting, receptor mediated delivery and improved intracellular trafficking in vitro and in vivo. Studies to evaluate the physicochemical properties, and the in vitro and in vivo performance of PEGylated and functionalised $\mathrm{Au}-\mathrm{L}$-cysteine nanoparticles as non-viral vectors for nucleic acid delivery are now in progress.

\section{Acknowledgements}

We acknowledge financial from the Irish Research Council, for a Government of Ireland Postdoctoral Fellowship to Jianfeng Guo (GOIPD/2013/150). Microscopy analysis was undertaken at the Electron Microscopy and Analysis Facility (EMAF) at the Tyndall National Institute, Cork, Ireland.

\section{References}

1 L. C. Cheng, X. Jiang, J. Wang, C. Chen and R. S. Liu, Nanoscale, 2013, 5, 3547-3569.

2 Y. Luo, M. Hossain, C. M. Wang, Y. Qiao, J. C. An, L. Y. Ma and M. Su, Nanoscale, 2013, 5, 687-694.

3 S. H. Wen, K. G. Li, H. D. Cai, Q. Chen, M. W. Shen, Y. P. Huang, C. Peng, W. X. Hou, M. F. Zhu, G. X. Zhang and X. Y. Shi, Biomaterials, 2013, 34, 1570-1580.

4 G. Barhate, M. Gautam, S. Gairola, S. Jadhav and V. Pokharkar, Int. J. Pharm., 2013, 441, 636-642.

5 L. J. Jing, X. L. Liang, Z. J. Deng, S. S. Feng, X. D. Li, M. M. Huang, C. H. Li and Z. F. Dai, Biomaterials, 2014, 35, 5814-5821.

6 L. Q. Shao, J. J. Diao, Z. P. Tang, S. Liu, S. C. Shen, J. K. Liu, X. F. Rui, D. P. Yu and Q. Zhao, Nanoscale, 2014, 6, 40894095.

7 A. Latorre, C. Posch, Y. Garcimartin, A. Celli, M. Sanlorenzo, I. Vujic, J. Ma, M. Zekhtser, K. Rappersberger, S. Ortiz-Urda and A. Somoza, Nanoscale, 2014, 6, 7436-7442.

8 K. Mallick and M. J. Witcomb, Gold Nanoparticles: Properties, Characterization and Fabrication, 2010, 225-243.

9 P. Ghosh, G. Han, M. De, C. K. Kim and V. M. Rotello, Adv. Drug Delivery Rev., 2008, 60, 1307-1315.

10 A. Kumar, X. Zhang and X. J. Liang, Biotechnol. Adv., 2013, 31, 593-606.

11 H. X. Cai and P. Yao, Nanoscale, 2013, 5, 2892-2900.

12 J. B. Song, Z. Fang, C. X. Wang, J. J. Zhou, B. Duan, L. Pu and H. W. Duan, Nanoscale, 2013, 5, 5816-5824.

13 A. Latorre, C. Posch, Y. Garcimartin, S. Ortiz-Urda and A. Somoza, Chem. Commun., 2014, 50, 3018-3020.

14 D. W. Kim, J. H. Kim, M. Park, J. H. Yeom, H. Go, S. Kim, M. S. Han, K. Lee and J. Bae, Biomaterials, 2011, 32, 25932604.

15 D. R. Bhumkar, H. M. Joshi, M. Sastry and V. B. Pokharkar, Pharm. Res., 2007, 24, 1415-1426.

16 W. H. Kong, K. H. Bae, S. D. Jo, J. S. Kim and T. G. Park, Pharm. Res., 2012, 29, 362-374. 
17 S. H. Lee, K. H. Bae, S. H. Kim, K. R. Lee and T. G. Park, Int. J. Pharm., 2008, 364, 94-101.

18 S. K. Lee, M. S. Han, S. Asokan and C. H. Tung, Small, 2011, 7, 364-370.

19 S. Y. Moon, T. Kusunose and T. Sekino, Mater. Lett., 2009, 63, 2038-2040.

20 R. Narayanan, R. J. Lipert and M. D. Porter, Anal. Chem., 2008, 80, 2265-2271.

21 J. Xiao and L. Qi, Nanoscale, 2011, 3, 1383-1396.

22 J. E. Millstone, S. J. Hurst, G. S. Métraux, J. I. Cutler and C. A. Mirkin, small, 2009, 5, 646-664.

23 Y. Huang, W. Wang, H. Liang and H. Xu, Cryst. Growth Des., 2009, 9, 858-862.

24 C. J. Murphy, A. M. Gole, J. W. Stone, P. N. Sisco, A. M. Alkilany, E. C. Goldsmith and S. C. Baxter, Acc. Chem. Res., 2008, 41, 1721-1730.

25 A. M. Alkilany, P. Nagaria, C. R. Hexel, T. J. Shaw, C. J. Murphy and M. D. Wyatt, Small, 2009, 5, 701-708.

26 M. Tarantola, A. Pietuch, D. Schneider, J. Rother, E. Sunnick, C. Rosman, S. Pierrat, C. Sönnichsen, J. Wegener and A. Janshoff, Nanotoxicology, 2011, 5, 254-268.

27 T. Mironava, M. Hadjiargyrou, M. Simon and M. H. Rafailovich, Nanotoxicology, 2014, 8, 189-201.

28 C. S. Yah, Biomed. Res., 2013, 24, 400-413.

29 C. J. Johnson, E. Dujardin, S. A. Davis, C. J. Murphy and S. Mann, J. Mater. Chem., 2002, 12, 1765-1770.

30 R. Chen, J. Wu, H. Li, G. Cheng, Z. Lu and C. M. Che, Rare Met., 2010, 29, 180-186.

31 S. E. A. Gratton, P. A. Ropp, P. D. Pohlhaus, J. C. Luft, V. J. Madden, M. E Napier and J. M. DeSimone, Proc. Natl. Acad. Sci. U. S. A., 2008, 105, 11613-11618.

32 C. M. Goodman, C. D. McCusker, T. Yilmaz and V. M. Rotello, Bioconjugate Chem., 2004, 15, 897-900.

33 T. Zhao, X. Shen, L. Li, Z. Guan, N. Gao, P. Yuan, S. Q. Yao, Q. H. Xu and G. Q. Xu, Nanoscale, 2012, 4, 7712-7719.

34 M. S. Dobrick, K. V. Sarathy and M. Jansen, J. Am. Chem. Soc., 2005, 127, 12816-12817.

35 J. Patel, L. Němcová, P. Maguire, W. G. Graham and D. Mariotti, Nanotechnology, 2013, 24, 245604.

36 W. J. Song, J.-Z. Du, T.-M. Sun, P. Z. Zhang and J. Wang, Small, 2009, 6, 239-246.

37 K. Esumi, N. Takei and T. Yoshimura, Colloids Surf., B, 2003, 32, 117-123.

38 A. Elbakry, E. C. Wurster, A. Zaky, R. Liebl, E. Schindler, P. B. Kreisel, T. Blunk, R. Rachel, A. Goepferich and M. Breunig, Small, 2012, 8, 3847-3856.

39 K. Rahme, M. T. Nolan, T. doody, G. P. McGlacken, M. A. Morris, C. O'Driscoll and a. J. D. Holmes, RSC Adv., 2013, 3, 21016-21024.

40 K. Rahme, L. Chen, R. G. Hobbs, M. A. Morris, C. O'Driscoll and a. J. D. Holmes, RSC Adv., 2013, 3, 6085-6094.

41 K. R. Brown and M. J. Natan, Langmuir, 1998, 14, 726-728.

42 K. R. Brown, L. A. Lyon, A. P. Fox, B. D. Reiss and M. J. Natan, Chem. Mater., 2000, 12, 314-323.

43 N. R. Jana, L. Gearheart and C. J. Murphy, Langmuir, 2001, 17, 6782-6786.
44 S. J. R. Meex, U. Andreo, J. D. Sparks and E. A. Fisher, J. Lipid Res., 2011, 52, 152-158.

45 M. J. O'Neill, J. F. Guo, C. Byrne, R. Darcy and C. M. O'Driscoll, Int. J. Pharm., 2011, 413, 174-183.

46 J. Guo, W. P. Cheng, J. Gu, C. Ding, X. Qu, Z. Yang and C. O'Driscoll, Eur. J. Pharm. Sci., 2012, 45, 521-532.

47 X. F. He, J. Wang, J. Dou, F. L. Yu, K. Cai, X. L. Li, H. Y. Zhang and N. Gu, Exp. Ther. Med., 2011, 2, 911-916.

48 F. Y. Huang, Y. N. Li, W. L. Mei, H. F. Dai, P. Zhou and G. H. Tan, Asian Pac. J. Trop. Med., 2012, 5, 169-174.

49 J. Guo, A. M. O'Mahony, W. P. Cheng and C. M. O'Driscoll, Int. J. Pharm., 2013, 447, 150-157.

50 J. Guo, J. R. Ogier, S. Desgranges, R. Darcy and C. O'Driscoll, Biomaterials, 2012, 33, 7775-7784.

51 B. Nikoobakht and M. A. El-Sayed, Langmuir, 2001, 17, 63686374.

52 T. K. Sau and C. J. Murphy, J. Am. Chem. Soc., 2004, 126, 8648-8649.

53 G. Oza, S. Pandey, R. Shah, M. Vishwanathan, R. Kesarkar, M. Sharon and M. Sharon, Adv. Appl. Sci. Res., 2012, 3, 1027-1038.

54 B. Nikoobakht and M. A. El-Sayed, Chem. Mater., 2003, 15, 1957-1962.

55 C. K. Wang, J. E. Wang, D. J. Liu and Z. X. Wang, Talanta, 2010, 80, 1626-1631.

56 L. Cao, T. Zhu and Z. Liu, J. Colloid Interface Sci., 2006, 293, 69-76.

57 W. Haiss, N. T. K. Thanh, J. Aveyard and D. G. Fernig, Anal. Chem., 2007, 79, 4215-4221.

58 S. Hong and X. Li, J. Nanomater., 2013, 790323.

59 K. Mallick, Z. L. Wang and T. Pal, J. Photochem. Photobiol., A, 2001, 140, 75-80.

60 C. Ziegler and A. Eychmuller, J. Phys. Chem. C, 2011, 115, 4502-4506.

61 Y. G. Kim, S. K. Oh and R. M. Crooks, Chem. Mater., 2004, 16, 167-172.

62 S. Link and M. A. El-Sayed, J. Phys. Chem. B, 1999, 103, 42124217.

63 N. G. Khlebtsov and L. A. Dykman, J. Quant. Spectrosc. Radiat. Transfer, 2010, 111, 1-35.

64 E. Boisselier and D. Astruc, Chem. Soc. Rev., 2009, 38, 17591782.

65 J. Guo, L. Bourre, D. M. Soden, G. C. O'Sullivan and C. O'Drisocll, Biotechnol. Adv., 2011, 29, 402-417.

66 R. Ghosh, L. C. Singh, J. M. Shohet and P. H. Gunaratne, Biomaterials, 2013, 34, 807-816.

67 J. Conde, F. Tian, Y. Hernández, C. Bao, D. Cui, K. P. Janssen, M. R. Ibarra, P. V. Baptista, T. Stoeger and J. M. de la Fuente, Biomaterials, 2013, 34, 7744-7753.

68 P. Resnier, T. Montier, V. Mathieu, J.-P. Benoit and C. Passirani, Biomaterials, 2013, 34, 6429-6443.

69 S. Borse, S. Joshi and A. Khan, RSC Adv., 2015, 5, 1340213410.

70 D. Zheng, D. A. Giljohann, D. L. Chen, M. D. Massich, X.-Q. Wang, H. Iordanov, C. A. Mirkin and A. S. Paller, Proc. Natl. Acad. Sci. U. S. A., 2012, 109, 11975-11980. 
71 A. Elbakry, A. Zaky, R. Liebkl, R. Rachel, A. Goepferich and M. Breunig, Nano Lett., 2009, 9, 2059-2064.

72 D. W. Pack, A. S. Hoffman, S. Pun and P. S. Stayton, Nat. Rev. Drug Discovery, 2005, 4, 581-593.

73 E. Lai and J. H. v. Zanten, Biophys. J., 2001, 80, 864-873.
74 J. V. Jokerst, T. Lobovkina, R. N. Zare and S. S. Gambhir, Nanomedicine, 2011, 6, 715-728.

75 K. Rahme, F. Gauffre, J. D. Marty, B. Payre and C. Mingotaud, J. Phys. Chem. C, 2007, 111, 7273-7279.

76 M. A. Mintzer and E. E. Simanek, Chem. Rev., 2009, 109, 259302. 